\title{
An examination of the role of chiasma frequency in the genetic system of marsupials
}

\author{
P. J. Sharp* and \\ D. L. Hayman
}

Genetics Department, University of Adelaide, Box 498, Adelaide 5001, Australia.

Chiasma frequencies have been collected from males of 33 species of marsupial, varying widely with respect to size, reproduction and development. Correlation analyses show that species with lower levels of recombination are smaller, have larger litters and develop more quickly. Two indices of recombination level were considered: Darlington's Recombination Index, and the Excess Chiasma frequency (chiasmata above one per bivalent). The EC is in general more strongly correlated than RI with aspects of life history. It is suggested that EC levels have evolved due to the effects of EC on recombination, but that chromosome number has evolved independently.

\section{INTRODUCTION}

Present knowledge of mammalian chromosome evolution is largely limited to comparisons between G-banded chromosomes from different species. Such studies consider evidence relating to the changes in chromosome structure which distinguish one karyotype from another. They utilise the features of chromosome number and morphology obtained from mitotic divisions. There are, by way of contrast, very few comparative studies of meiosis in mammals. Consequently, little information is available about the variation in the number and distribution of chiasmata present between related species.

Comparative chromosome evolution has been well studied in Australian marsupial species and considerable detail is known about the mitotic complements (Rofe and Hayman, 1985; Hayman et al., 1987). As an extension of these studies meiosis has been examined in some 33 species. This paper reports on the results of these studies on chiasma frequency and considers a possible interpretation of the data based upon aspects of the biology of the different species.

\footnotetext{
* Present address: Plant Breeding Institute, Maris Lane, Trumpington, Cambridge CB2 2LQ, U.K.
}

\section{MATERIALS AND METHODS}

\section{The species studied}

In order to make the best use of what is known of the cytology of marsupials, and in particular the knowledge of the chromosomal relationships between the different species, the species examined in this study have been arranged into two groups (table 1).

Those in Group 1 are all non-macropodid species. The group contains two subgroups. The first contains species which all possess a morphologically similar chromosome complement with a common major G-band pattern (Rofe and Hayman, 1985). The taxonomically diverse species in this subgroup show an extensive range of adaptations. The few chromosome differences between species are limited to those which occur within a chromosome, such as inversions. The other subgroup includes species which do not have the common $2 n=14$ complement. There is a range of chromosome number from $2 n=16$ to $2 n=24$ in this subgroup, and the majority of species are from the family Petauridae.

Species in Group 2 are all members of the family Macropodidae. These species have similar biological features, are closely related in evolutionary terms, and many pairs of species are capable of forming viable though sterile hybrids. The group 
Table 1 The species studied

\begin{tabular}{|c|c|c|c|}
\hline Superfamily & Family & Species & $\begin{array}{l}\text { Number } \\
\text { examined }\end{array}$ \\
\hline \multicolumn{4}{|l|}{ Group 1} \\
\hline \multirow[t]{6}{*}{ Dasyuroidea } & \multirow[t]{6}{*}{ Dasyuridae } & Sminthopsis crassicaudata & 17 \\
\hline & & Sminthopsis murina & 1 \\
\hline & & Dasyuroides byrnei & 4 \\
\hline & & Dasyurus hallucatus & 1 \\
\hline & & Dasyurus viverrinus & 3 \\
\hline & & Sarcophilus harrisii & 3 \\
\hline \multirow[t]{4}{*}{ Perameloidea } & \multirow[t]{4}{*}{ Peramelidae } & Perameles gunnii & 4 \\
\hline & & Perameles nasuta & 1 \\
\hline & & Isoodon obesulus & 3 \\
\hline & & Isoodon macrourus & 1 \\
\hline \multirow[t]{3}{*}{ Vombatoidea } & \multirow{3}{*}{$\begin{array}{l}\text { Phascolarctidae } \\
\text { Vombatidae }\end{array}$} & Phascolarctos cinereus & 1 \\
\hline & & Lasiorhinus latifrons & 2 \\
\hline & & Vombatus ursinus & 1 \\
\hline \multirow[t]{4}{*}{ Phalangeroidea } & \multirow[t]{2}{*}{ Petauridae } & Petaurus breviceps & 2 \\
\hline & & Pseudocheirus peregrinus & 3 \\
\hline & \multirow[t]{2}{*}{ Phalangeridae } & Trichosurus vulpecula & $69^{*}$ \\
\hline & & Trichosurus arnhemensis & 1 \\
\hline Tarsipedoidea & Tarsipedidae & Tarsipes rostratus & 1 \\
\hline \multicolumn{4}{|l|}{ Group 2} \\
\hline & \multirow[t]{15}{*}{ Macropodidae } & Potorous tridactylus & 1 \\
\hline & & Setonix brachyurus & 3 \\
\hline & & Lagorchestes conspicillatus & 2 \\
\hline & & Bettongia penicillata & 1 \\
\hline & & Bettongia lesueur & 2 \\
\hline & & Thylogale billardierii & 1 \\
\hline & & Wallabia bicolor & 1 \\
\hline & & Macropus parma & 1 \\
\hline & & Macropus eugenii & 3 \\
\hline & & Macropus agilis & 1 \\
\hline & & Macropus parryi & 1 \\
\hline & & Macropus rufogriseus & 1 \\
\hline & & Macropus robustus & 1 \\
\hline & & Macropus giganteus & 1 \\
\hline & & Macropus rufus & 1 \\
\hline
\end{tabular}

* Data reported fully in Sharp and Hayman (1985)

exhibits a considerable range in both chromosome number $(2 n=12-22)$ and morphology. G-banding studies show that each specific chromosome complement is derivable from a single $2 n=$ 22 complement by simple fusion events (Rofe, 1978; Hayman et al., 1987).

\section{The recombination data}

Meiotic divisions were obtained from the testes of healthy adult males using the technique described by Sharp (1982) which produces clear preparations of diplotene cells (fig. 1). At least 20 such cells were analysed in almost all the individuals examined, and the average chiasma frequency was calculated for each species. There may be sig- nificant differences in chiasma frequency between individuals within a given species, so that it is desirable to examine meiosis in a number of individuals in arriving at an estimate of chiasma frequency. Where possible this has been done. In one species Trichosurus vulpecula an extensive analysis of chiasma frequency variation in 69 males showed no effect of either age or season (Sharp and Hayman, 1985).

There is now convincing evidence that chiasmata at diplotene indicate the sites of recombination (Tease and Jones, 1978; Kando and Kato, 1980). The position of a chiasma may affect the genetic significance of the actual recombination event. In particular, chiasma localisation markedly restricts the amount of recombination that can 

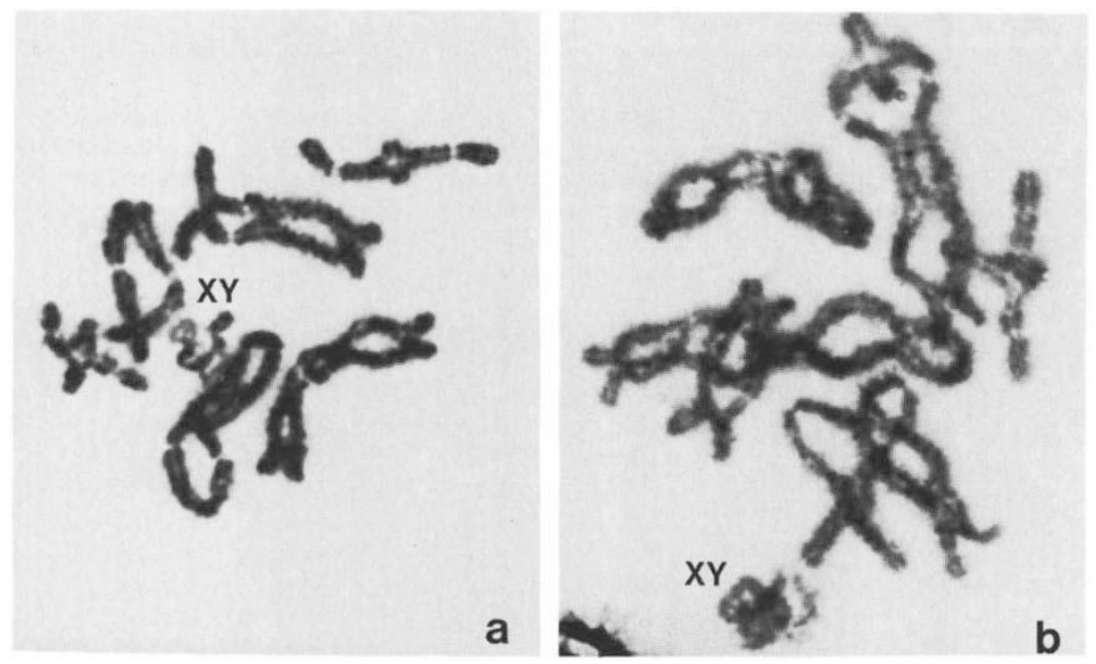

Figure 1 Diplotene meiocytes from male (a) Isoodon macrourus, and (b) Lasiorhinus latifrons. The XY sex bivalents are indicated.

occur. No evidence of strongly localised distal or proximal chiasmata was seen in any of the species studied, although this does not rule out the possibility that a degree of chiasma localisation has occurred in one or more species. Further, both within and between species with the same chromosome number and morphology, such as the $2 n=14$ subgroup, the chiasmata were distributed proportionally to chromosome length (results not shown).

The average chiasma frequency was used to calculate two measures of recombination for each species, the recombination index (RI), and the excess chiasma frequency (EC). The RI is the sum of the haploid chromosome number and the average chiasma frequency (Darlington, 1939), and estimates the number of independently segregating units at meiosis. Its use allows comparisons of the total amount of resulting recombination to be made between species with different chromosome numbers. The EC has been defined as the number of chiasmata in addition to those necessary to ensure regular segregation (Burt and Bell, 1987), and is calculated as the difference between the average chiasma frequency and the haploid chromosome number. Since there are no chiasmata between the sex chromosomes in male marsupials (Sharp 1982) we have used the haploid number of autosomes in calculating both indices (table 3).

\section{The biological data}

Data were collected from the literature on some biological features of the species studied (table 2).
These include indices of the rate of development and of reproduction since these were considered as likely to be correlated with the frequency of recombination.

The metrics employed involve

(a) Size: The physical size of a species is represented by head-body length (exclusive of tail length since not all species have tails) and weight. Some of the species are sexually dimorphic with respect to size and in these the values given are the means of the sexes.

(b) Development: Three indices of the rate of development were used; length of gestation, time from birth to weaning, and the age of the females of the species at their first breeding. Where there may be delayed implantation (embryonic diapause), especially in macropodids, the data given are the lengths of gestation in the absence of diapause. The time from birth to weaning includes the length of pouch life plus the time the young continue to suckle after leaving the pouch.

(c) Reproductive potential: The two indices used were the number of young weaned per mating, and numbers of litters per female in a year. In macropodids (Group 2) this measure is complicated by the possibility that at any one time females may have two young; one "at foot" and still suckling, one in the pouch as well as a delayed blastocyst. The value given for such species is a maximum number of young weaned in a year. The annual reproductive potential of a species can be regarded as the number of young weaned per litter multiplied 
Table 2 Biological features of the species studied



* The initials only of each species are given, the complete names are in table 1

Data collected from Wood Jones (1923-5), Ride (1970), Collins (1973), Tyndale-Biscoe (1973), Kaufmann (1974), Stonehouse and Gilmore (1977), Rose (1978), Wells (1978), Hyett (1980), Gemmel (1982), Lee et al., (1982), Morton (1982), Rose and McCartney (1982), Russell (1982) and Strahan (1983)

by the number of litters per year. No numerical value could be given for this latter component as the available data are too sketchy, but an indication is given of whether multiple reproduction in a year is common, occasional or absent.

(d) Sociality: Kaufmann (1974) reviewed what is known of social organisation in macropodids. His bar graphs (based on observations of the size and permanence of groups) were used to provide rank scores of sociality.

In addition, comparative measures of nuclear DNA content and chromosome number were incorporated in the analyses. Statistical tests were made using Spearman's non-parametric rank correlation coefficient $\left(r_{s}\right)$. This was used since the data do not satisfy the requirements for applying Pearson's correlation coefficients, and although the individual biological datum points may be revised by subsequent work it is unlikely that this would change the ranking of the species for any characTER. The significance of the calculated $r_{s}$ values was tested by calculating a $t$-test value, or in cases where the sample size was small (less than 12), by reference to table 87 of Bishop (1980). 
Table 3 Karyotypic features and meiotic recombination

\begin{tabular}{|c|c|c|c|c|c|}
\hline Species & $2 n$ & $\begin{array}{l}\text { Relative } \\
\text { DNA content* }\end{array}$ & $\begin{array}{l}\text { Average cell } \\
\text { chiasma frequency }\end{array}$ & $\mathrm{RI}^{\dagger}$ & $\mathrm{EC}^{\dagger}$ \\
\hline \multicolumn{6}{|l|}{ Group 1} \\
\hline$S c$ & 14 & $86 \cdot 4$ & $13 \cdot 64$ & $19 \cdot 64$ & $7 \cdot 64$ \\
\hline$S m$ & 14 & - & $13 \cdot 50$ & $19 \cdot 50$ & $7 \cdot 50$ \\
\hline$D b$ & 14 & $86 \cdot 4$ & $17 \cdot 40$ & $23 \cdot 40$ & $11 \cdot 40$ \\
\hline$D h$ & 14 & $86 \cdot 4$ & $18 \cdot 75$ & $24 \cdot 75$ & $12 \cdot 75$ \\
\hline$D v$ & 14 & - & $18 \cdot 93$ & $24 \cdot 93$ & $12 \cdot 93$ \\
\hline$S h$ & 14 & $86 \cdot 4$ & $20 \cdot 83$ & $26 \cdot 83$ & $14 \cdot 84$ \\
\hline$P g$ & 14 & - & $12 \cdot 66$ & $18 \cdot 66$ & $6 \cdot 66$ \\
\hline$P n$ & 14 & 109 & $13 \cdot 98$ & $19 \cdot 98$ & $7 \cdot 98$ \\
\hline Io & 14 & 116 & $16 \cdot 27$ & $22 \cdot 27$ & $10 \cdot 27$ \\
\hline Im & 14 & 114 & $16 \cdot 30$ & $22 \cdot 30$ & $10 \cdot 30$ \\
\hline$P c$ & 16 & $93 \cdot 3$ & $23 \cdot 40$ & $30 \cdot 40$ & $16 \cdot 40$ \\
\hline$L l$ & 14 & $103 \cdot 6$ & $22 \cdot 43$ & $28 \cdot 43$ & $16 \cdot 43$ \\
\hline$V u$ & 14 & 102 & $22 \cdot 20$ & $28 \cdot 20$ & $16 \cdot 20$ \\
\hline $\mathrm{Pb}$ & 22 & - & 14.90 & $24 \cdot 90$ & $4 \cdot 90$ \\
\hline$P p$ & 20 & 154 & $16 \cdot 80$ & $25 \cdot 80$ & $7 \cdot 80$ \\
\hline$T v$ & 20 & 102 & $18 \cdot 14$ & $27 \cdot 14$ & $9 \cdot 14$ \\
\hline$T a$ & 20 & - & $16 \cdot 55$ & $25 \cdot 55$ & $7 \cdot 55$ \\
\hline $\operatorname{Tr}$ & 24 & - & $22 \cdot 95$ & $44 \cdot 95$ & 11.95 \\
\hline \multicolumn{6}{|l|}{ Group 2} \\
\hline$P t \ddagger$ & $13 \delta^{\circ}, 129$ & - & 20.95 & 26.95 & 14.95 \\
\hline$S b$ & 22 & 93.8 & $29 \cdot 28$ & $39 \cdot 28$ & $19 \cdot 28$ \\
\hline$L c \S$ & $15{ }^{\circ}, 169$ & $90 \cdot 3$ & $16 \cdot 24$ & $22 \cdot 24$ & $8 \cdot 24$ \\
\hline$B p$ & 22 & - & $28 \cdot 40$ & $38 \cdot 40$ & $18 \cdot 40$ \\
\hline$B l$ & 22 & - & $23 \cdot 35$ & $33 \cdot 35$ & $13 \cdot 35$ \\
\hline$T b$ & 22 & $84 \cdot 5$ & $24 \cdot 65$ & $34 \cdot 65$ & 14.65 \\
\hline$W b \ddagger$ & $11 \delta^{\circ}, 10 \%$ & $97 \cdot 7$ & $14 \cdot 18$ & $19 \cdot 18$ & $9 \cdot 18$ \\
\hline$M p$ & 16 & $98 \cdot 6$ & 23.45 & $30 \cdot 45$ & $16 \cdot 45$ \\
\hline$M e$ & 16 & $98 \cdot 2$ & $23 \cdot 00$ & $30 \cdot 00$ & 16.00 \\
\hline$M a$ & 16 & $97 \cdot 7$ & $17 \cdot 75$ & $24 \cdot 75$ & $10 \cdot 75$ \\
\hline Mpy & 16 & $124 \cdot 6$ & 16.90 & 23.90 & 9.90 \\
\hline$M r f$ & 16 & $116 \cdot 1$ & $20 \cdot 90$ & $27 \cdot 90$ & $13 \cdot 90$ \\
\hline$M r b$ & 16 & $104 \cdot 1$ & $31 \cdot 70$ & $38 \cdot 70$ & $24 \cdot 70$ \\
\hline$M g$ & 16 & 100 & $32 \cdot 35$ & $39 \cdot 35$ & $25 \cdot 35$ \\
\hline$M r$ & 20 & 103.9 & 37.90 & 46.90 & $28 \cdot 90$ \\
\hline
\end{tabular}

* From Hayman and Martin (1974) using $M g$ as their standard. $\dagger$ RI and EC are defined in the text. $\ddagger$ These two species have an $\mathrm{X}$-autosome translocation as a regular feature of their karyotype. The chiasmata in the autosomal arm are included in the data. $\S$ This species has both $\mathrm{X}$ - and $\mathrm{Y}$-autosome interchanges, and the chiasmata in the autosomal arms are included in the data

\section{RESULTS}

The data on nuclear DNA content, chiasma frequency and the calculated indices of recombination are shown in table 3 . The data relating to the life histories of the species are given in table 2 . Correlation coefficients between the levels of recombination and the components of life histories and karyotypic features were calculated and are summarised in Tables 4-7.

Table 4 presents the results of the analyses performed on all the species. The majority of the correlations are significant, with correlations with the EC being in general of higher numerical value. Tables 5 and 6 present the same correlation coefficients for Groups 1 and 2. In the analysis of the macropodids (Group 2), all species produce only one pouch young at a time, so this parameter is not included, but an analysis of the data on sociality is included. The non-macropodids (Group 1) showed a similar pattern of correlation coefficients to the analysis considering all the species, whereas in the macropodids (Group 2) no significant correlations were found apart from the predictable one of RI with $2 n$. The analysis for the two large groups of species with the same chromosome number, the $2 n=14$ non-macropodids and the $2 n=16$ macropodids are given in Table 7 . The majority of the correlations for the $2 n=14$ group are significant, but none are significantly different from zero for the $2 n=16$ macropodids. 
Table 4 Correlations between various features and the two indices of recombination

\begin{tabular}{llllll}
\hline Feature & \multicolumn{2}{c}{ RI } & Significance & $\begin{array}{l}\text { EC } \\
r_{s}\end{array}$ & Significance \\
\hline Head-body length & $N$ & $r_{s}$ & Signt & +0.60 & $* * *$ \\
Weight & 33 & +0.41 & $*$ & +0.62 & $* * *$ \\
Gestation time & 33 & +0.43 & $*$ & +0.60 & $* *$ \\
Birth $\rightarrow$ weaning time & 27 & +0.46 & $*$ & +0.57 & $* * *$ \\
No. of pouch young & 31 & +0.49 & $* *$ & -0.30 & ns \\
\& age at 1st breeding & 33 & -0.35 & $*$ & +0.52 & $* *$ \\
DNA content & 33 & +0.33 & ns & -0.07 & ns \\
2n & 24 & -0.01 & ns & +0.21 & ns \\
\hline
\end{tabular}

Footnotes to Tables 4-7

ns $=$ not significantly different from zero, $* P<0.05$, ** $P<0.01$, *** $P<0.001$

$N=$ number of species in comparison. It varies within the tables because not all information was available for each species (see table 3). The degrees of freedom used in testing the significance of the $r_{s}$ value $=N-2$

$r_{s}=$ Spearman's rank correlation coefficient

Table 5 Correlations between various features and the two measures of recombination in the non-macropodids (Group 1)

\begin{tabular}{|c|c|c|c|c|c|}
\hline Feature & $N$ & $\begin{array}{l}\mathrm{RI} \\
r_{s}\end{array}$ & Significance & $\begin{array}{l}\mathrm{EC} \\
r_{s}\end{array}$ & Significance \\
\hline Head-body length & 18 & +0.53 & $*$ & +0.56 & $*$ \\
\hline Gestation time & 13 & +0.80 & $* * *$ & +0.67 & $*$ \\
\hline Birth $\rightarrow$ weaning time & 18 & $+0 \cdot 82$ & $* * *$ & +0.61 & $* *$ \\
\hline No. of pouch young & 18 & -0.52 & $*$ & -0.08 & ns \\
\hline $2 n$ & 18 & +0.59 & $* *$ & -0.06 & ns \\
\hline
\end{tabular}

\section{DISCUSSION}

The approach adopted in this study has been to test the null hypothesis that there is no association between aspects of life history and recombination. The analysis presented in table 4 disproves this null hypothesis. All the correlations between recombination and the life history aspects considered are significant. The correlations suggest that those species with higher levels of recombination tend to be larger, slower developing, and to produce fewer pouch young.

The two large groups of species give different results. The non-macropodids (Group 1, table 5) which cover a range of chromosome numbers, show the same overall pattern of significant correlations as in table 4. The macropodids (Groups 2), a more closely integrated taxonomic group, have

Table 6 Correlations between various features and the two measures of recombination in the macropodids (Group 2)




Table 7 Correlations between various features and chiasma frequency in the $2 n=14$ species and the $2 n=16$ macropodids

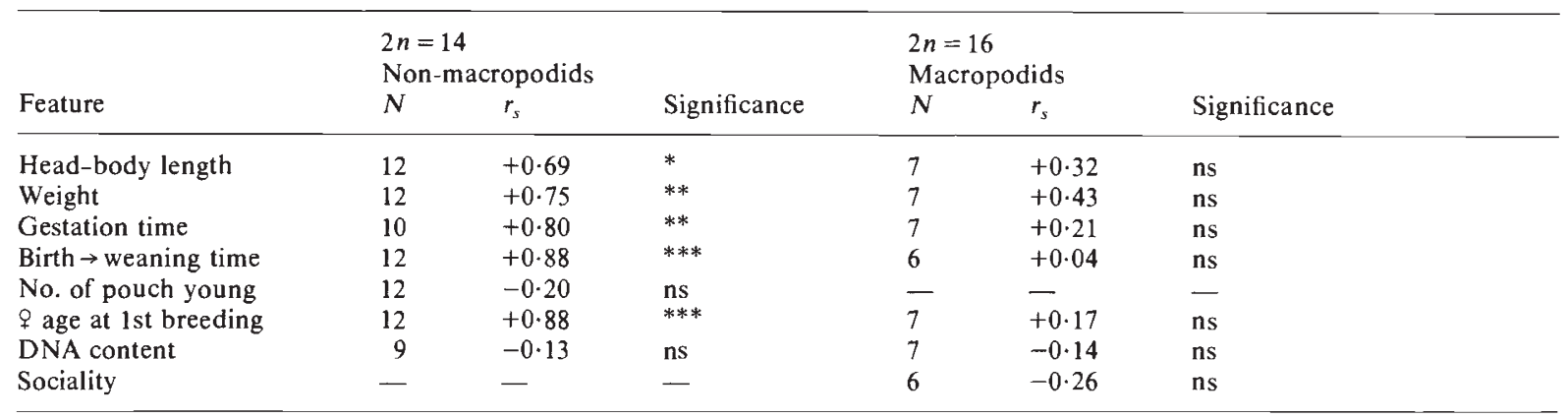

a substantial range of chromosome numbers, and an especially wide range of recombination indices, but have a limited range of life history strategies compared to non-macropodids. The significant correlations evidenced in non-macropodids are absent from macropodids (table 6). This difference may be related to the fact that all the macropodids give birth to one young at a time and are not as diverse a group with respect to reproductive characters. This, however, still does not explain the role played by the substantial range in both recombination indices in macropodids. However, as most of the data for macropodids came from one individual per species the between individual variation (Sharp and Hayman, 1985) might have produced a greater variation in the recombination indices in this group.

In table 7 the correlations are shown for the two large groups of species of common chromosome number. Those species with the conserved complement of $2 n=14$ enable correlations to be considered where the morphological aspects of the chromosomal phenotype are kept constant. The extreme diversity of adaptations present in this group shows clear correlations with chiasma frequency which varies over a two-fold range. Only the correlation of recombination level and the number of pouch young is not significant. This calculation does not take into account the annual number of young reared, which would be more highly correlated with recombination as the smaller species have multiple reproduction each year (table 2). In contrast, the correlations between recombination level and the biological features considered in the $2 n=16$ macropodids were not significant, even though the species have a two-fold range of chiasma frequency. However, the underlying trend in the macropodids and nonmacropodids may well be the same, since the signs of the calculated correlation coefficients are the same (compare tables 5 and 6 , and the $2 n=14$ and $2 n=16$ groups in table 7 ), with the exception of factors concerning reproductive rate where almost all macropodids have only one young per year. In this situation, any correlation between either gestation time or time from birth to weaning and recombination may be expected to be less strong or absent.

Two indices of recombination were considered, Darlington's recombination index and the excess chiasma frequency. It appears that the EC might be a more useful index to use in comparative studies where chromosome number varies. In comparing the full range of species (table 4) the EC is more strongly correlated with the biological features. Additionally, in all comparisons, the EC and chromosome number are not correlated. It has been suggested that chromosome number varies due to other pressures such as social organisation and drift (Wilson et al., 1975; Bengtsson, 1980), which would appear to operate irrespective of their subsequent effect on the level of recombination, so that only the EC might be easily open to evolutionary modification due to its effect on recombination level (Darlington, 1932; John and Lewis 1975). The other karyotypic feature considered, DNA content, was not correlated with either of the indices of recombination.

The only study comparable to the present report is that of Burt and Bell (1987). They collected chiasma frequency data of 24 wild mammals (including four marsupials) from the published literature and found a strong positive relationship of the RI and EC with both age to maturity and weight, and negative correlations with litter size. In addition, they found that the correlations with EC were stronger than those with RI, and that EC was not correlated with $2 n$. The two studies therefore show the same associations, and demonstrate the biological significance of the EC. Burt and Bell (1987) also found that domesticated mammals have higher recombination levels than expected on the basis of the correlations in the wild species (as suggested by Hayman (1981) by analogy with 
results from plant studies), demonstrating that the EC can be adjusted quickly in evolutionary terms. The associations that have been found in marsupials here, and by Burt and Bell (1987), are reminiscent of those that have been reported in plants (Grant, 1958; Stebbins, 1958). Additionally, the marsupials with low levels of recombination resemble the organisms recognised by Mather (1953) as having an apparent compromise between releasing variation by rapid population turnover, and conserving variation by having lower rates of meiotic recombination.

As Burt and Bell (1987) indicate, the associations found across species between recombination levels and biological features may help distinguish between two models of the evolution of recombination, the "Red Queen" and "Tangled Bank", reviewed by Maynard Smith (1978), Bell (1982) and Charlesworth (1985). The Red Queen model, which suggests that recombination has been selected because the biotic environment of each species is continually becoming more hostile, predicts that species with longer generations will have higher levels of recombination due to the stronger selection for genetic diversity they face in comparison to species with shorter generations. The species with longer generations (those with slower development) in both the mammals studied by Burt and Bell (1987), and in the marsupials discussed here do have higher levels of recombination, lending support to the Red Queen model. The Tangled Bank model proposes that recombination has been favoured as it produces genetically diverse sibs which are each more likely to survive sib competition, and therefore predicts that species with more intense sib competition will have higher recombination levels. Unfortunately, data on levels of sib competition are not available. Burt and Bell (1987) assumed that sib competition is positively correlated with litter size, and concluded that the lack of positive correlation between recombination level and litter size was evidence against the Tangled Bank model. However, it may be that the level of sib competition is not strongly correlated with litter size, but depends more on factors such as the degree of dispersal of sibs and the level of sociality of a species. Certainly, the Red Queen model does not predict the negative correlations between recombination levels and litter sizes observed both by Burt and Bell (1987) and here in the marsupials.

The correlation analyses reported here were performed separately for each component of life history as if these were independent of each other. Clearly, this is not the case. The various com- ponents of life history are themselves inter-correlated though no single "Index of Life History" exists or seems possible. Grant (1975) suggested that many aspects of the genetic system of different species might be related to the ecological concepts of $r$ - and $K$-selection (MacArthur and Wilson, 1967; Pianka, 1970). Certainly marsupial species which are large, develop slowly and have few pouch young (characteristics expected under $K$-selection) tend to have higher recombination levels than those which are small, rapidly developing and with a greater production of pouch young (characteristics expected under $r$-selection).

A deficiency of this study, as with almost all other studies of chiasma frequency, is that data have been collected from one sex only. Differences in chiasma frequency and distribution are known to exist between the sexes in some eutherian mammals (Polani, 1972) and lower vertebrates (Callan and Perry, 1977). However, it would be remarkable if the situation in females of the species considered here was the reverse of that described in the males, so that the level of recombination of the species as a whole and their life history components were not correlated.

A novel difference has been reported in the marsupial Sminthopsis crassicaudata, where recombination is very much lower in the female than in the male (Bennett et al., 1986), but it is not known if this is a feature of other marsupials. Interestingly, S. crassicaudata has one of the lowest male recombination levels (table 2), so the extremely low level in the female of this species might possibly be an extension of the situation in the male.

Clearly, a definitive assessment of how useful data on chiasma frequency will be in accommodating the different strategies employed by mammals will depend on further studies. It would be surprising, however, if such a potentially important feature played an insignificant role in the genetic systems of mammals.

Acknowledgements We are greatly indebted to the following people who provided or allowed access to the animals studied; Prof. J. H. Bennett, Dr W. Breed, and Dr M. J. Smith (University of Adelaide); Dr R. Baker (Adelaide Zoo); Dr D. King and Dr A. Oliver (APB of WA); Prof A. Bradshaw and Prof. J. Shield (University of Western Australia); Dr J Nelson (Monash University); Pastor I. Wittwer, Cleve; Dr P. Baverstock (IMVS, Adelaide); Dr G. Lyne (CSIRO, Division of Wildlife Research); and the South Australian and Tasmanian National Parks and Wildlife Services. Mrs D. Golding helped with animal handling and husbandry. PJS was the recipient of a Commonwealth Postgraduate Research Award, and we also thank the M.V. Ingham Trust for financial assistance. A. Burt and G. Bell kindly provided a copy of their paper before publication. We thank Dr R. N. Jones and Prof B. John for discussions. 


\section{REFERENCES}

BENNETT, J. H., HAYMAN, D. L. AND HOPE, P. M. 1986. Novel sex difference in linkage values and meiotic chromosome behaviour in a marsupial. Nature, 233, 59-60.

BELL, G. 1982. The Masterpriece of Nature. Croom Helm, London.

BISHOP, O. N. 1981. Statistics for Biology: A practical guide for the experimental biologist, 3rd edition. Longman, New York.

BURT, A. AND BELL, G. 1987. Mammalian chiasma frequencies: A critical test of two theories of recombination. Nature, 326, 803-805.

CALLAN, H. G. AND PERRY, P. E. 1977. Recombination in male and female meiocytes contrasted. Phil. Trans. R. Soc. Lond. B. $277,227-233$.

CHARLESWORTH, B. 1985. Recombination, genome size and chromosome number. In Cavalier-Smith, T. (ed.) The Evo lution of Genome Size, Wiley-Interscience, Chichester.

COLLINS, L. R. 1973. Monotremes and Marsupials-A Reference for Zoological Institutions. Smithsonian Inst. Press, Washington.

DARLINGTON, C. D. 1932. Recent Advances in Cytology. J. and A. Churchill, London.

DARLINGTON, C. D. 1939. The Evolution of Genetic Systems. Cambridge University Press.

GEMMEL, G. T. 1982. Breeding bandicoots in Brisbane (Isoodon macrourus; Marsupialia, Peramelidae), Aust. Mammal., 5, 187-193.

GRANT, V. 1958. The regulation of recombination in plants. Cold Spring Harbor Symp. Quant. Biology. 23, 337-363.

GRANT, V. 1975. The Genetics of Flowering Plants. Columbia University Press.

HAYMAN, D. L. 1981. Components of genetic systems in mammals. In Atchley, W. R. and Woodruff, D. (eds.) Evolution and Speciation: Essays in Honor of M. J. D. White, Cambridge University Press.

HAYMAN, D. L. AND MARTIN, P. G. 1974. Mammalia I: Monotremata and Marsupialia. Vol. 4: Chordata 4. In John, B. (ed.) Animal Cytogenetics, Borntraeger, Berlin.

HAYMAN, D. L., ROFE, R. H. AND SHARP, P. J. 1987. Chromosome Evolution in Marsupials. Chromosomes Today, Vol. 9, 91-102.

HYETT, J. 1980. Austrialian Mammals-A field guide for New South Wales, South Australia, Victoria and Tasmania. Nelson, Melbourne.

JOHN, B. AND LEWIS, K. R. 1975. Chromosome Hierarchy: An Introduction to the Biology of the Chromosome. Oxford University Press.

KANDO, N. AND KATO, H. 1980. Analysis of crossing over in mouse meiotic cells by BrdU labelling technique Chromosoma, 78, 113-122.

KAUFMANN, J. H. 1974. The ecology and evolution of social organization in the kangaroo family (Macropodidae). Amer. Zool. 14, 51-62.

LEE, A. K., WOOLLEY, P. AND BRAithWAiTe, R. W. 1982. Life history strategies of dasyurid marsupials. In Archer, M. (ed.) Carnivorous Marsupials, Roy. Zool. Soc. NSW, Sydney.
MACARTHUR, R. H. AND WILSON, E. O. 1967. The Theory of Island Biography. Princeton University Press.

MATHER, K. 1953. The genetical structure of populations. Symp. Soc. Exp. Biol., 7, 66-95

MAYNARD SMITH, J. 1978. The Evolution of Sex. Cambridge University Press.

MORTON, S. R. 1982. Dasyurid marsupials of the Australian arid zone; An ecological review. In Archer, M. (ed.) Carnivorous Marsupials, Roy. Zool. Soc. NSW., Sydney.

PIANKA, E. R. 1970. On $r$ - and $K$-selection. Amer. Natur., 104, 592-597.

POLANI, P. E. 1972. Centromere localization at meiosis and the position of chiasmata in the male and female mouse. Chromosoma, 36, 343-374.

ROFE, R. H. 1978. G-banded chromosomes and the evolution of Macropodidae. Aust. Mammal., 2, 52-62.

ROFE, R. H. AND HAYMAN, D. 1985. G-band evidence for a conserved complement in the Marsupialia. Cytogenet. Cell Genet., 39, 40-50.

ROSE, R. W. 1978. Reproduction and evolution in female Macropodidae. Aust. Mammal., 2, 56-72.

ROSE, R. W. AND MCCARTNEY, D. J. 1982. Growth of the Red-bellied Pademelon, Thylogale billardierii, and age estimation of pouch young, Aust. Wildl. Res. 9, 33-38.

RIDE, W. D. L. 1970 A Guide to the Native Mammals of Australia. Oxford University Press, Melbourne.

RUSSELL, E. M. 1982. Patterns of parental care and parental investment in marsupials. Biol. Rev., 57, 423-486.

SHARP, P. J. 1982. Sex chromosome pairing during meiosis in marsupials. Chromosoma, 86, 27-47.

SHARP, P. J. AND HAYMAN, D. L. 1985. Variation in chiasma frequency in male Trichosorus vulpecula (Marsupialia: Mammalia). Genetica, 66, 145-150.

STEBBINS, G. L. 1958. Longevity, habitat and release of genetic variability in the higher plants. Cold Spring Harbour Symp. Quant. Biol., 23, 365-378.

STONEHOUSE, B. AND GILMORE, D. 1977. The Biology of Marsupials. Macmillan, London.

Strahan, R. 1983. Complete Book of Australian Mammals. Angus and Robertson, and the Australian Museum, Melbourne.

TEASE, C. AND JONES, G. H. 1978. Analysis of exchanges in differentially stained meiotic chromosomes of Locusta migratoria after BrdU-substitution and FPG staining I. Crossover exchanges in monochiasmate bivalents. Chromosoma, 69, 163-178.

TYNDALE-BISCOE, H. 1973. Life of Marsupials, Edward Arnold, London.

WELLS, R. T. 1978. Field observations of the Hairy-Nosed Wombat, Lasiorhinus latifrons (Owen). Aust. Wildl. Res., 5, 299-303.

WILSON, A. C., BUSH, G. L., CASE, S. M. AND KING, M. C. 1975. Social structuring of mammalian populations and the rate of chromosomal evolution. Proc. Nat. Acad. Sci. USA, 72, $5061-5065$.

WOOD JONES, F. 1923-25. The Mammals of South AustraliaParts I-III. Government Printer, Adelaide. 